\title{
THE ANALYSIS OF THE DEFORMATION STATE OF THE DOUBLE-WAVE GUARDRAIL MOUNTED ON BRIDGES AND VIADUCTS OF THE MOTOR ROADS IN LITHUANIA AND UKRAINE
}

\author{
Olegas Prentkovskis ${ }^{1}$, Jurijus Tretjakovas ${ }^{2}$, Audrius $\breve{S ̌ v e d a s}^{3}$, Andrii Bieliatynskyi ${ }^{4}$, \\ Alfonsas Daniūnas ${ }^{5}$, Kateryna Krayushkina ${ }^{6}$ \\ ${ }^{1}$ Department of Transport Technological Equipment, Vilnius Gediminas Technical University, \\ Plytinès g. 27, LT-10105 Vilnius, Lithuania \\ ${ }^{2}$ Department of Strength of Materials, Vilnius Gediminas Technical University, \\ Sauletekio al. 11, LT-10223 Vilnius, Lithuania \\ ${ }^{3}$ Forensic Science Centre of Lithuania, Lvovo g. 19a, LT-09313 Vilnius, Lithuania \\ ${ }^{4,6}$ Department of Airport Reconstruction and Automobile Roads, Institute of Airports, \\ National Aviation University, Kosmonavta Komarova ave 1, 03680 Kiev, Ukraine \\ ${ }^{5}$ Department of Steel and Timber Structures, Vilnius Gediminas Technical University, \\ Sauletekio al. 11, LT-10223 Vilnius, Lithuania \\ E-mails: ${ }^{1}$ olegas.prentkovskis@vgtu.lt (corresponding author); ${ }^{2}$ jurijus.tretjakovas@vgtu.lt; \\ 3audrius.svedas@gmail.com; ${ }^{4}$ beljatynskij@mail.ru; ${ }^{5}$ alfonsas.daniunas@vgtu.lt; ${ }^{6}$ ekrayushkina@yandex.ua \\ Received 29 Nov. 2010; accepted 5 Jan. 2012

\begin{abstract}
Traffic safety mainly depends on vehicles, pedestrians and road infrastructure. On highways, the heaviest traffic accidents are associated with crossing of the dividing strips by a vehicle and its collision with side obstacles on the junction or road bridge exit. These accidents often occur, when vehicles, running at a high speed, collide with obstacles, which may cause human injuries. In such cases, the probability of fatalities or heavy injuries to people in a traffic accident is very high. Road traffic infrastructure plays an important part in ensuring traffic safety on urban roads and highways. It includes guardrails, speed bumps, pedestrian safety islands, traffic regulation systems, road information infrastructure, etc. Guardrail (known as civil engineering element and traffic safety element) installation may help to reduce the number of human injuries and fatalities caused by traffic accidents. Guardrails of various types are installed on the roads of Lithuania and Ukraine. Guardrails, consisting of metal posts of the profile $\Sigma$ and a protective beam of the profile W, i.e. 'doublewave guardrails', are among the most commonly used ones. The authors of this paper present the analysis of the deformation state of a double-wave guardrail (describing the strains and stresses of its elements).
\end{abstract}

Keywords: traffic safety, motor road, traffic accident, guardrail, post, beam, deformation state, stress, deflection, finite element method.

\section{Introduction}

It is believed that the development of road transport has a positive effect on economic and social development. Motorization level has been increasing in recent years and is likely to be increasing in the near future. However, it has a number of negative effects as well - these are traffic accidents and a decrease in traffic safety in some countries. According to the statistical data (Fig. 1), the total number of people killed (per million population) in road accidents in the EU Member-States in 2011 is equals the one in 1772 (Accident Rate Information 2011).

Traffic safety mainly depends on vehicles, pedestrians and road infrastructure. High accident rate on the roads of Lithuania (and other countries) is accounted for by such factors as irresponsible behaviour of drivers and pedestrians on the road, poor traffic control, the road state, etc. Traffic culture, mutual respect and mutual aid of people on the road are still rather low.
The main causes of traffic accidents are as follows: traffic rules are violated by car drivers (who exceed the speed limit, ignore the road signs and signals, etc.); traffic rules are violated by pedestrians (who cross the road where they like, are absent-minded, etc.; technical vehicle defects (in the brakes, steering gear, etc.); poor state of the road (slippery pavement, poor lighting and insufficiently developed road infrastructure, etc.).

Every year, the Traffic Police of Lithuania register traffic accidents (Accident Rate Information 2011). The dynamics of the traffic accidents registered in 2000-2011 is shown in Fig. 2. In 2011, 3312 traffic accidents were registered. Their distribution (in percent) is given in Fig. 3. In Fig. 4, the percent distribution of traffic accident guilty parties in 2011, is shown.

The dependences graphically presented in Figs $2-4$ show that:

- in recent years, the number of the registered traffic accidents in Lithuania has been decreasing; 
- the largest number of traffic accidents are associated with 'Collision of vehicles', 44\%;

- most of the traffic accidents are caused by 'Drivers', 66\%;

- the smallest number of traffic accidents are associated with 'Grounding on an obstacle', 3.5\%, which may be a guardrail, a lamp post, a tree, a gate, etc.

On highways, the heaviest traffic accidents are associated with crossing of the dividing strips by a vehicle and its collision with side obstacles on the junction or road bridge exit. These accidents often occur, when vehicles,

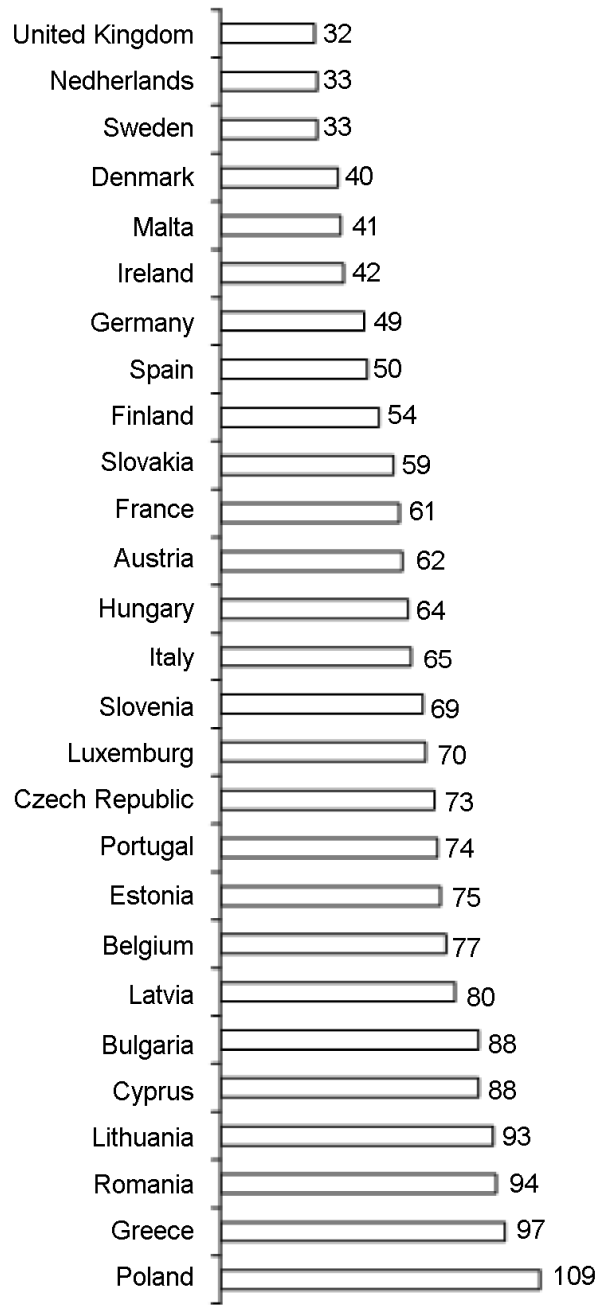

Fig. 1. The distribution of the number of people killed (per million population) in road accidents in the EU Member-States in 2011

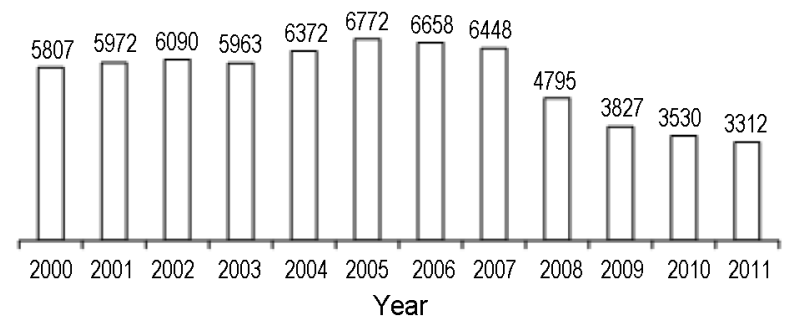

Fig. 2. The dynamics of traffic accidents registered by the Traffic Police of Lithuania in 2000-2011

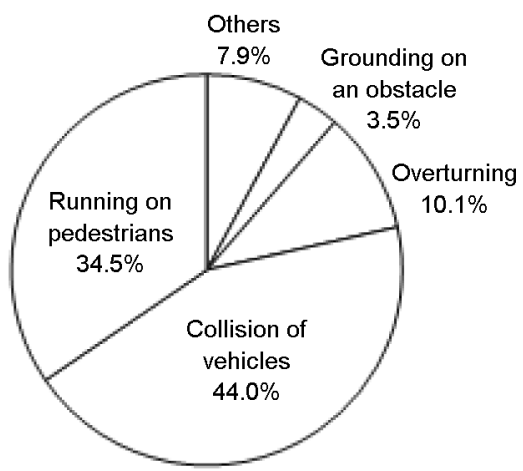

Fig. 3. The percent distribution of traffic accidents in Lithuania in 2011 (total number of registered accidents - 3312)

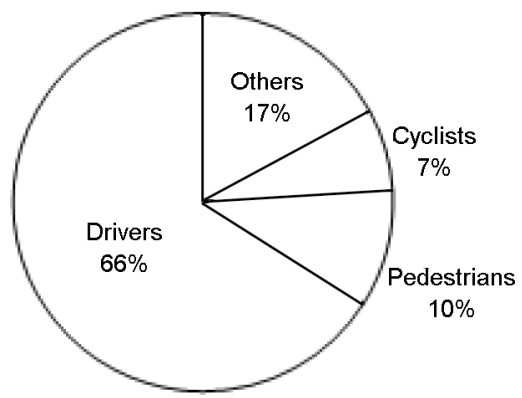

Fig. 4. The percent distribution of traffic accident guilty parties in Lithuania in 2011 (total number of registered accidents 3312)

running at a high speed, collide with obstacles, which may cause human injuries. In such cases, the probability of fatalities or heavy injuries to people in a traffic accident is very high.

Guardrail (known as civil engineering element and traffic safety element) installation may help to reduce the number of human injuries and fatalities caused by traffic accidents. It is assumed that guardrails should be installed only at dangerous road exits or for preventing from driving into the obstacles, the collision with which may cause more serious accidents than the collision with a guardrail. The dividing guardrails on multilane roads should prevent from the accidents associated with crossing the dividing strip. Crashworthy guardrails are power absorbing structures which are installed in front of stationary obstacles, making a part of road structure, e.g. an underpass approach, overbridge elements of the junction exit at various levels or a bridge pier.

Ideally, a guardrail should 'grip' a vehicle and guide it to the controlled stop. It is of paramount importance that a vehicle, colliding with a guardrail, should not be thrown back on the lane at the same speed at which it was running. Moreover, guardrails should be installed so that they could not reduce visibility on the road, particularly, on the route sections with decreased visibility.

The transport system of any country has three constituent parts: road (route), passengers (goods) and vehicles. All of them, taken individually or in interaction, strongly affect road traffic safety. The researchers all over the world investigate the problem of traffic safety. In particular, some of them (Mučinis et al. 2009; Ambrozi- 
ak, Korzeniowski 2010; Hassan, Al-Jabri 2011; Hartleb, Ketting 2011; Wang et al. 2011a; Sivilevičius 2011a; Sivilevičius et al. 2011; Krayushkina et al. 2012; Li et al. 2012 , etc.) focus on the study of pavement quality, while others (Beljatynskij et al. 2009; Prentkovskis et al. 2009, 2010a, b; Černiauskas et al. 2010; Žiliūtè et al. 2010; Dargužis et al. 2011; Dell'Acqua, Russo 2011; Kopczyński etal. 2011; Maksymowicz et al. 2011; Keršys et al. 2011; Mucha et al. 2011; Sapragonas, Dargužis 2011; Wang et al. 2011b; Ptak et al. 2012, etc.) concentrate on investigating active and passive measures, ensuring vehicle safety. There are also works, dealing with the problems of passengers and freight safety in transportation (Grīslis 2010; Jahangiri et al. 2011; Jović, Đorić 2010; Matis 2010; Žiliūtė et al. 2010; Jablonskytė et al. 2011; Sharma et al. 2011; Stanić et al. 2011, etc.) and interaction between various elements of transport systems (Beljatynskij et al. 2009; Prentkovskis et al. 2009, 2010b; Jakimavičius, Burinskienė 2010; Abtahi et al. 2011; Bień 2011; Dargužis et al. 2011; Iluk, Rusiński 2011; Jablonskytė et al. 2011; Sivilevičius 2011b; Keršys et al. 2011; Ptak et al. 2012), etc.

Road traffic infrastructure plays an important part in ensuring traffic safety on urban roads and highways. It includes guardrails, speed bumps, pedestrian safety islands, traffic regulation systems, road information infrastructure, etc.

The problems, associated with the investigation and increase of motor road guardrail safety, have been in the focus of the researchers in various countries for many years. Let us describe some of them:

- Cable guardrail systems received the increased attention due to their low installation cost and excellent safety performance. This led to an increase in the use of non-linear finite element modelling for the design and analysis of such systems. However, previously used wire rope models were not validated with physical testing. Stolle and Reid (2011) developed a wire rope model for cable guardrail simulation;

- Ferdous et al. (2011) carried out limit performance analysis for common roadside and median barriers using LS-DYNA software. In the considered research, finite element models, developed for four widely used guardrail systems, were analysed. The selected guardrail systems are the modified G4(1S) $\mathrm{W}$-beam and three-beam guardrails, as well as Midwest guardrail system and modified weak post W-beam guardrail. LS-DYNA simulations, using these guardrail models, were validated, based on the results obtained in the commonly used crash tests performed on flat terrain;

- Tan et al. (2008) focussed on designing motorcyclist-friendly guardrails, using finite element analysis. They developed three-dimensional computer models, consisting of a newly designed V-beam guardrail and the equivalent kinetic characteristics of a motorcycle. The collision between a motorcycle and a guardrail was then simulated, using the finite element computer program -
ALGOR. The simulations were conducted for three impact configurations, with the impact angle between the motorcycle and the guardrail making $90^{\circ}, 45^{\circ}$ and $20^{\circ}$ at the impact velocity of $60 \mathrm{~km} / \mathrm{hr}$. The results showed that the newly designed V-beam guardrail had better energy absorption characteristics than the existing conventional W-beam guardrail design;

- Wu and Thomson (2005) investigated the effects of the front wheels and steering-suspension systems during the oblique vehicle collisions with a flared guardrail terminal. The Swedish National Road Administration presented a new design for terminals of roadside guardrails, i.e. a flared guardrail terminal, mounted on the inner embankment of a ditch. The flared guardrail terminal was modelled and two vehicle models were modified with LS-DYNA to simulate an oblique impact situation. The goal of the simulations was to improve the vehicle models by refining their wheels and steering-suspension systems for better prediction and reproduction of the vehicle behaviour during oblique collisions with guardrails;

- In their another work, Wu and Thomson (2007) carried out a study of the interaction between a guardrail post and soil during quasi-static and dynamic loading. A parametric study was subsequently conducted to investigate the influence of gravel stiffness on the soil-post interaction through computer simulations using LS-DYNA;

- Finite element modelling and validation of a 3 -strand cable guardrail system was carried out by Mohan et al. (2005). In this work, a detailed finite element model of a three-strand cable guardrail was developed and validated against a previously conducted full-scale crash test. The full-scale crash test and simulation were set up for an impact of the cable guardrail with a $2000 \mathrm{~kg}$ pickup truck at an angle of $25^{\circ}$ and the initial velocity of $100 \mathrm{~km} / \mathrm{hr}$. The detailed methods for system simulation involving dynamic interactions of soil/post, post/hook bolts, cable/hook bolts and cable/truck were also discussed;

- Crash performance of a strong-post W-beam guardrail with missing blockouts was investigated by Hampton and Gabler (2012). Missing blockouts in a strong-post W-beam guardrail, a condition most commonly associated with environmental decay or crash damage, has never been thoroughly investigated. Finite element models were developed for three pendulum tests. The simulation results indicated that wheel snagging was not a major problem. Although a missing blockout increases the maximum rail tension and deflection by as much as $13 \%$, such guardrails are still capable of safely redirecting the vehicles;

- Bayton et al. (2008) examined the effect of a full impact vehicle crash test on the joint material and the mechanical fasteners that form part of the safety barrier beam-to-beam connection joint; 
- Ren and Vesenjak (2005) carried out computational and experimental crash analysis of the road safety barrier. A computational model of a vehicle, guardrail and its interaction was designed in LS-DYNA software. The new road safety guardrail was tested in a full-scale crash test The crash test was carried out with the FIAT Uno as the impacting vehicle under the same initial impact conditions as those used in the simulations. The comparison of computational and experimental results proved the correctness of the computational model;

- It should be noted that the above investigations make only a part of the research works in the area of guardrail application. In fact, thousands of them have been performed.

Guardrails of various types are installed on the roads of Lithuania and Ukraine. Guardrails, consisting of metal posts of the profile $\Sigma$ and a protective beam of the profile W, i.e. 'double-wave guardrails' (see Fig. 5), are among the most commonly used ones.

The authors of this paper present the analysis of the deformation state of a double-wave guardrail (describing the strains and stresses of its elements).

a)

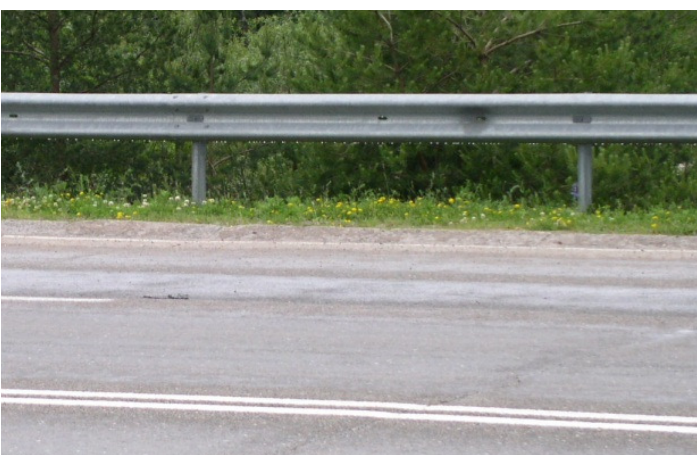

b)

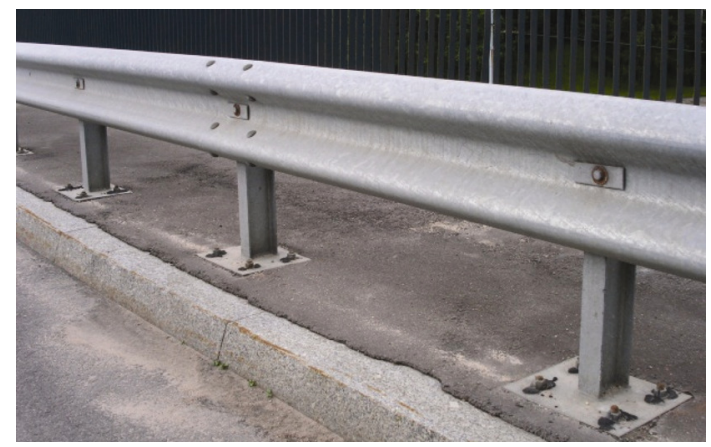

Fig. 5. The double-wave guardrails, most commonly used on Lithuanian and Ukrainian roads (our photos)

\section{The application of the finite element method to the analysis of guardrails}

\subsection{General information}

A modern concept of the finite element method (FEM) is very broad. It embraces not only the approximate mathematical solution of differential equations by applying partial derivatives, but is often perceived as calculation methodology and even a universal approach to perfor- mance analysis of physical and engineering objects or systems (Zienkiewicz et al. 2005; Moaveni 2008; Logan 2011). FEM is an approximate mathematical method aimed at solving differential equations of partial derivatives. However, as regards its engineering application, it is more suitable to relate it to the particular classes of some applied problems and their specific features.

A motor road guardrail (Fig. 5) is modelled, using 3-D finite elements SOLID186 (Fig. 6). SOLID186 is a higher order 3-D 20-node solid element that exhibits quadratic displacement behavior. The element is defined by 20 nodes having three degrees of freedom per node: translations in the nodal $X, Y$, and $Z$ directions. The element supports plasticity, hyper elasticity, creep, stress stiffening, large deflection and large strain capabilities (http://www.ansys.com).

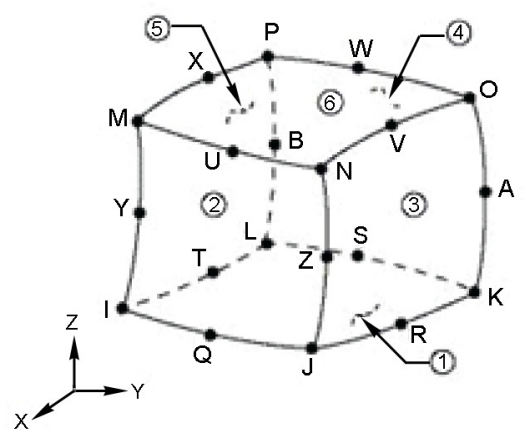

Fig. 6. A 3-D 20-node finite element SOLID186 (Moaveni 2008)

\subsection{Theoretical aspects of guardrail analysis}

A guardrail is a mechanical system. To derive an equation of motion of the finite element, the Lagrange equation of the second kind is used (Zienkiewicz et al. 2005; Prentkovskis et al. 2009, 2010a).

Then, the expressions of the kinetic and potential energy, as well as dissipative finite element function and the vector of the external forces, acting on the finite element, are written (Prentkovskis et al. 2009, 2010a), taking into account that the displacements in the finite element are approximated as follows:

$$
\left\{u^{(e)}\right\}=[N]\left\{q^{(e)}\right\},
$$

where: $\left\{u^{(e)}\right\}$ is the displacement in the finite element; $[N]$ denotes the finite element shape functions; $\left\{q^{(e)}\right\}$ is the vector of generalized displacements of the finite element.

Substituting the expressions of the kinetic and potential energy, the dissipative function of the finite element and the vector of the external forces, acting on it, into the Lagrange equation of the second kind, a system of motion equations for the finite element is obtained in the matrix form:

$$
\left[M^{(e)}\right]\left\{\ddot{q}^{(e)}\right\}+\left[C^{(e)}\right]\left\{\dot{q}^{(e)}\right\}+\left[K^{(e)}\right]\left\{q^{(e)}\right\}=\left\{F^{(e)}\right\},
$$


where: $\left[M^{(e)}\right],\left[C^{(e)}\right],\left[K^{(e)}\right]$ are matrices of finite element masses, mechanical energy suppression and stiffness; $\left\{\ddot{q}^{(e)}\right\},\left\{\dot{q}^{(e)}\right\},\left\{q^{(e)}\right\}$ are vectors of generalized accelerations, velocities and displacements of the finite element.

Integrating the motion equations of all finite elements into a general system, a system of motion equations is obtained for a motor road guardrail:

$$
\begin{gathered}
{\left[M_{\text {guardrail }}\right]\left\{\ddot{q}_{\text {guardrail }}\right\}+\left[C_{\text {guardrail }}\right]\left\{\dot{q}_{\text {guardrail }}\right\}+} \\
{\left[K_{\text {guardrail }}\right]\left\{q_{\text {guardrail }}\right\}=\left\{F_{\text {guardrail }}\right\},}
\end{gathered}
$$

where: $\left[M_{\text {guardrail }}\right],\left[C_{\text {guardrail }}\right],\left[K_{\text {guardrail }}\right]$ are matrices of guardrail masses, mechanical energy suppression and stiffness; $\left\{\ddot{q}_{\text {guardrail }}\right\}, \quad\left\{\dot{q}_{\text {guardrail }}\right\}$, $\left\{q_{\text {guardrail }}\right\}$ are vectors of accelerations, velocities and displacements of all guardrail nodes; $\left\{F_{\text {guardrail }}\right\}$ is the vector of generalized forces, acting on the guardrail:

$$
\begin{array}{ll}
{\left[M_{\text {guardrail }}\right]=\sum_{e=1}^{N E}\left[M^{(e)}\right] ;} & {\left[C_{\text {guardrail }}\right]=\sum_{e=1}^{N E}\left[C^{(e)}\right] ;} \\
{\left[K_{\text {guardrail }}\right]=\sum_{e=1}^{N E}\left[K^{(e)}\right] ;} & \left\{F_{\text {guardrail }}\right\}=\sum_{e=1}^{N E}\left\{F^{(e)}\right\} ; \\
\left\{\ddot{q}_{\text {guardrail }}\right\}=\sum_{e=1}^{N E}\left\{\ddot{q}^{(e)}\right\} ; & \left\{\dot{q}_{\text {guardrail }}\right\}=\sum_{e=1}^{N E}\left\{\dot{q}^{(e)}\right\} ; \\
\left\{q_{\text {guardrail }}\right\}=\sum_{e=1}^{N E}\left\{q^{(e)}\right\}, &
\end{array}
$$

where: $N E$ is the number of finite elements.

To obtain the matrices of masses, mechanical energy suppression and finite element stiffness, the deformation of the finite element is investigated (Prentkovskis et al. 2009, 2010a).

The mass matrix $\left[M_{\text {guardrail }}\right]$, the mechanical energy suppression matrix $\left[C_{\text {guardrail }}\right]$ and the matrix of the finite element stiffness $\left[K_{\text {guardrail }}\right]$, the displacement vector $\left\{\ddot{q}_{\text {guardrail }}\right\}$, the vector of velocities $\left\{\dot{q}_{\text {guardrail }}\right\}$, the displacement vector $\left\{q_{\text {guardrail }}\right\}$ of the finite element and the vector of the generalized forces $\left\{F_{\text {guardrail }}\right\}$ are presented in the local system of the coordinates. Then, the matrices and the vectors are transformed into the global system of the coordinates.

\subsection{A brief description of FEM software packages}

The finite element method aims to break up large parts into a number of finite details. Then, each of them is cal- culated individually as an independent body with its own loads and stresses. When the calculation is over, a general stress and strain state of the part is presented.

A great number of universal and specialized computer programs, based on the finite element method, have been created. The universal programs, such as ANSYS, ALGOR, ABAQUS, COSMOS, etc., allow designers to investigate, check or predict the properties of the designed systems at the design stage. In fact, almost all academic or research institutes use lots of specialized finite element programs, created by their researchers for research or solution of particular engineering problems. Coupled with automatic geometric design and integrated programs (e.g. AutoCAD, MicroStation, CATIA, ProEngineer, Euclid, etc.), finite element programs make a powerful mathematical tool for modelling geometric and physical systems (Moaveni 2008).

The authors of the present paper chose the finite element software package ANSYS for investigating the guardrails of the motor roads.

ANSYS is a multifunctional finite element software package aimed at analysing and solving engineering and physical problems. This software package allows for solving both research and applied engineering problems. It has some supplements adapted to solving the particular area problems, for example, ANSYS Workbench, which is used for solving mechanical problems (Moaveni 2008).

\subsection{The creation of a discrete model}

To save computer resources and to reduce the number of calculations, only a fragment of the motor road guardrail is analysed. The models consist of two posts and the connecting beam (Fig. 7).

The distance between the posts is $2 \mathrm{~m}$. Posts of three various profiles and beams of two various profiles are modelled. The guardrail posts and beams are chosen according to the Standard Construction Recommendations R37-1 in 'Guardrails of Motor Roads' (2001) issued by the Board of Directors of the Lithuanian Road Administration under the Ministry of Transport and Communications of the Republic of Lithuania (valid till 2010), and according to both the Design Rules of Road Restraint Systems KPT TAS 09 (2010) and the Lithuanian Standard LST EN 1317 'Road Restraint Systems'. The analogical standards are valid for guardrails mounted in Ukraine (GOST 26804-86 valid till 30 November 2012, DSTU 2735-94, DSTU 3587-97, DSTU B V.2.3-28:2011 valid since 1 December 2012). The dimensions of the considered guardrail posts and beams correspond to those, given in the above document (Fig. 8).

Analysing the guardrail by the software package ANSYS, the authors divided the guardrail model into 3-D finite elements (SOLID 186) (Figs 6, 9). Each of these elements has 20 nodes, while each node has three degrees of freedom, $X, Y$ and $Z$, in the direction of the axes.

The case, when the guardrail is mounted on the bridge or viaduct is analysed. The posts of the guardrail are concreted to the depth of $15 \mathrm{~cm}$ from the road surface (boundary conditions in cyan colour, Fig. 9). This part of the guardrail is firmly fixed. In modelling, based on 


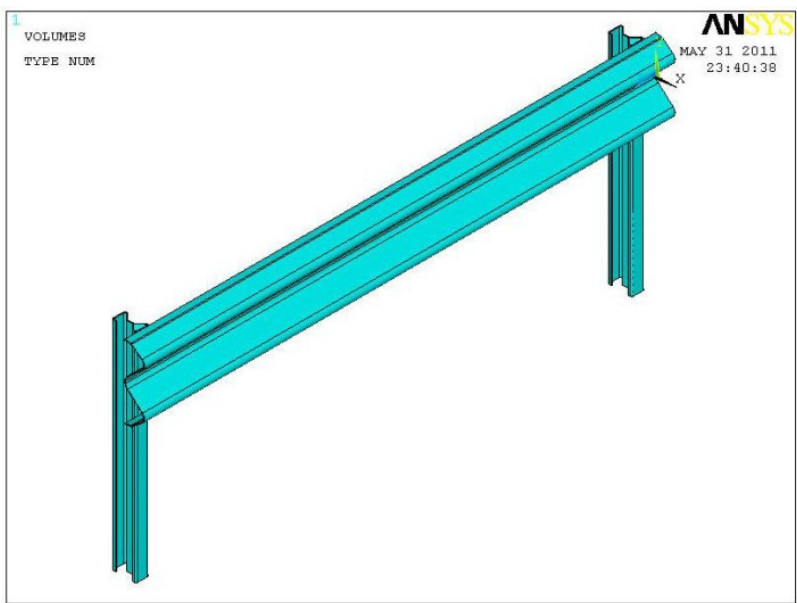

Fig. 7. The computer model of the guardrail part (our research)
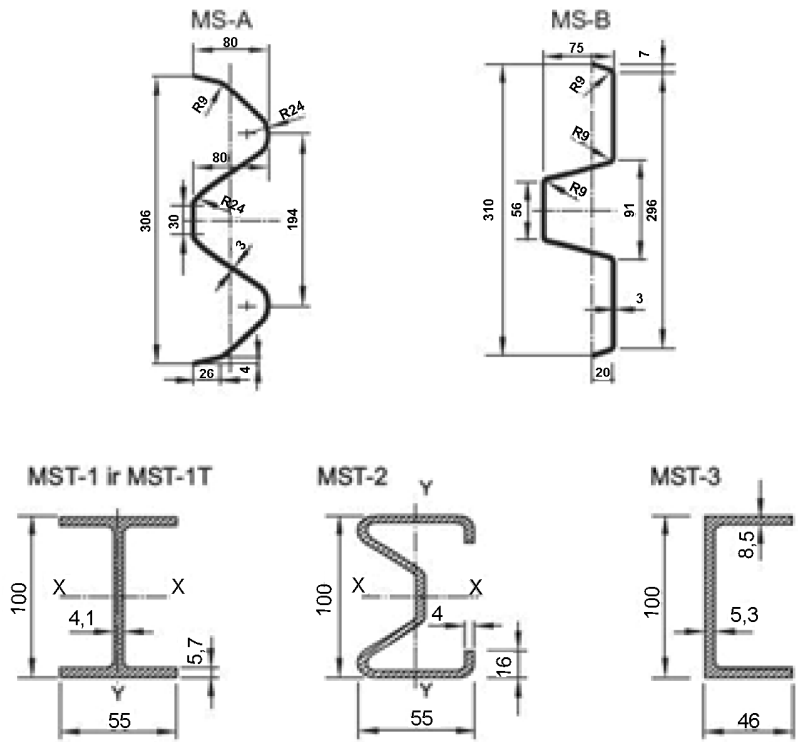

Fig. 8. Cross-sections of metal beams and posts (R37-1 2001)

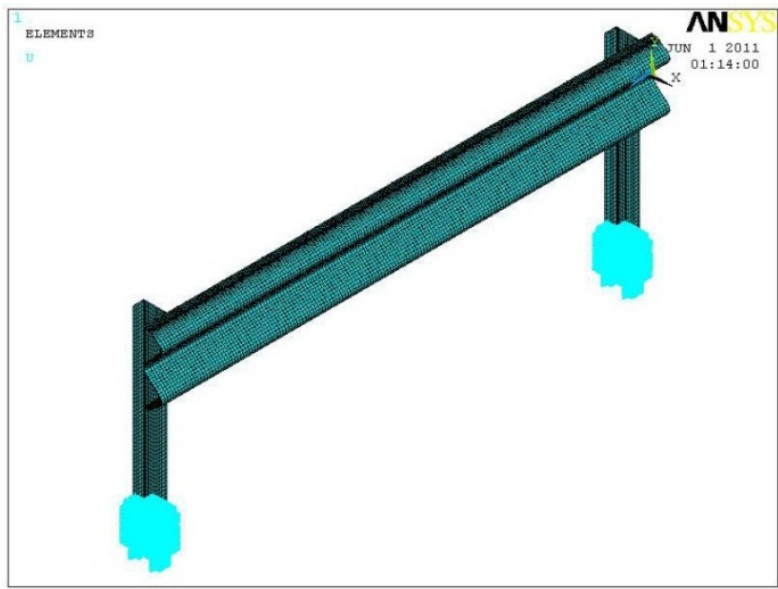

Fig. 9. The computer model of the guardrail with fixed (concreted) posts (boundary conditions in cyan colour) is divided into finite elements (our research) the use of the software package ANSYS, it is assumed that the displacements (degree of freedom of the nodes) of the part concreted into the base of bridge or viaduct are equal to zero in any direction.

The developed models are acted upon by the force of $150 \mathrm{kN}$. The force value was selected to meet the requirements of the Construction Regulations STR 2.05.04:2003 'Impacts and Loads'. The forces were applied at six points near the outward bends of the beams to imitate the width of the vehicle frame.

The results of the modelling are presented graphically in the software package ANSYS. The deflections and stresses of the guardrail posts and beams are also shown.

\section{The results obtained in computer-aided simulation and their analysis}

As mentioned above, the model of the motor road guardrail was developed and solved, using the software package ANSYS. In this section, the results obtained in computer-aided testing and their analysis are presented.

\subsection{The analysis of the guardrail posts}

The calculation of the post models, using ANSYS, yielded the results, which are given in Figs 10-12. The most valuable data refer to deflections and first principal stresses $(S 1)$ of structural elements (both maximum and those found at any point of the structure).

The analysis of the model for the case, when the posts were concreted at the depth of $15 \mathrm{~cm}$ on bridges or viaducts has shown that the post MST-2 had the largest deflection of $4.9 \mathrm{~cm}$ (Fig. 11). Smaller deflections of $4.4 \mathrm{~cm}$ and $2.6 \mathrm{~cm}$, respectively, were found in the posts MST-3 (Fig. 12) and MST-1 (Fig. 10). Since the post MST-1 has the smallest deflection, it is preferable for use on bridges or viaducts because, in this case, it is highly important that a vehicle should remain in the traffic lane after the collision with a guardrail. The smaller the deflection, the higher the probability that a vehicle will stay on the road.

The stresses of the posts of the guardrails mounted on a bridge or a viaduct are similarly distributed in all models. The highest stresses $(S 1)$ are found near the road pavement (Figs 10-12). The stresses are weakening in the direction of the top of the post. It is clear that there are also contact stresses, but they are outside the scope of the present study.

\subsection{The analysis of the guardrail beams}

The comparative analysis of the deflections of the guardrail beams yielded some unexpected results (Figs 13-14).

The deflection of the beam MS-B (6.7 cm, Fig. 14) was larger than that of the beam MS-A (3.5 cm, Fig. 13). This shows that the beam MS-B is more easily deformed than the beam MS-A and, therefore, absorb more impact energy during the collision of a vehicle with a guardrail (Prentkovskis et al. 2009, 2010a). Thus, the beam MS-B is preferable for guardrails, though, until now, the beam MS-A has been mostly used on Lithuanian and Ukrainian roads. 

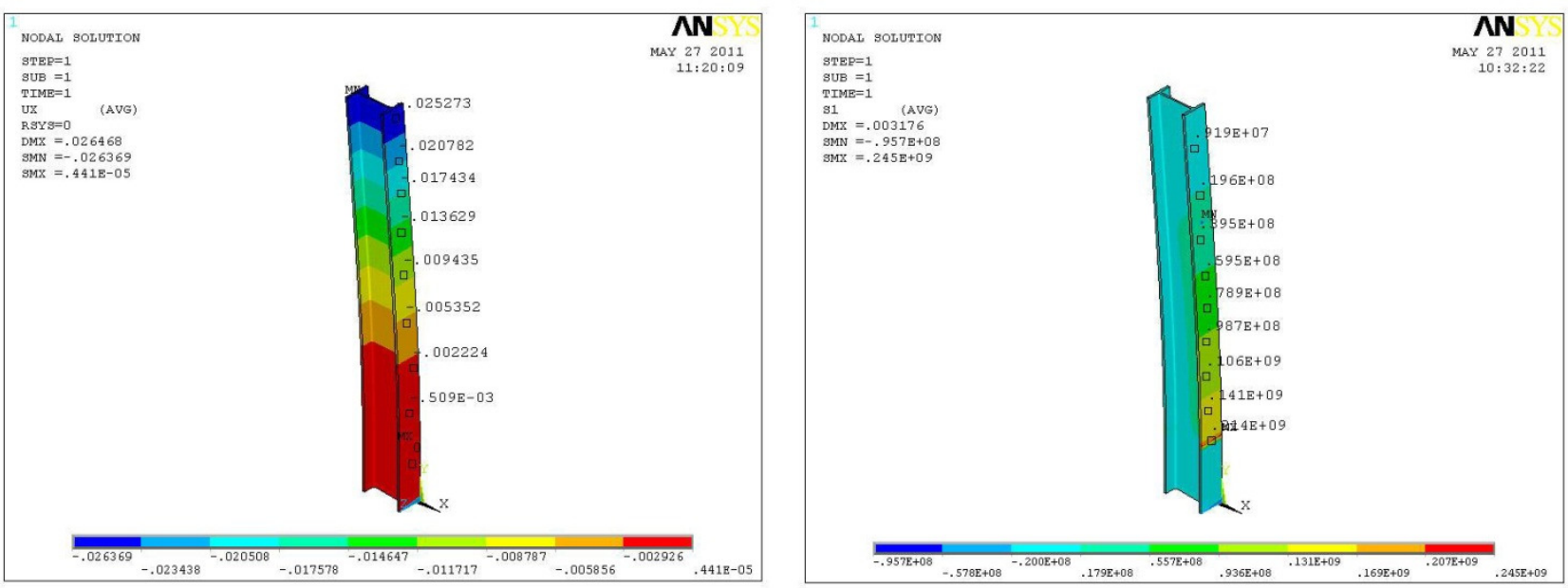

a)

b)

Fig. 10. The post MST-1 mounted on a bridge or a viaduct: $a$ - deflections, b-stresses (our research)
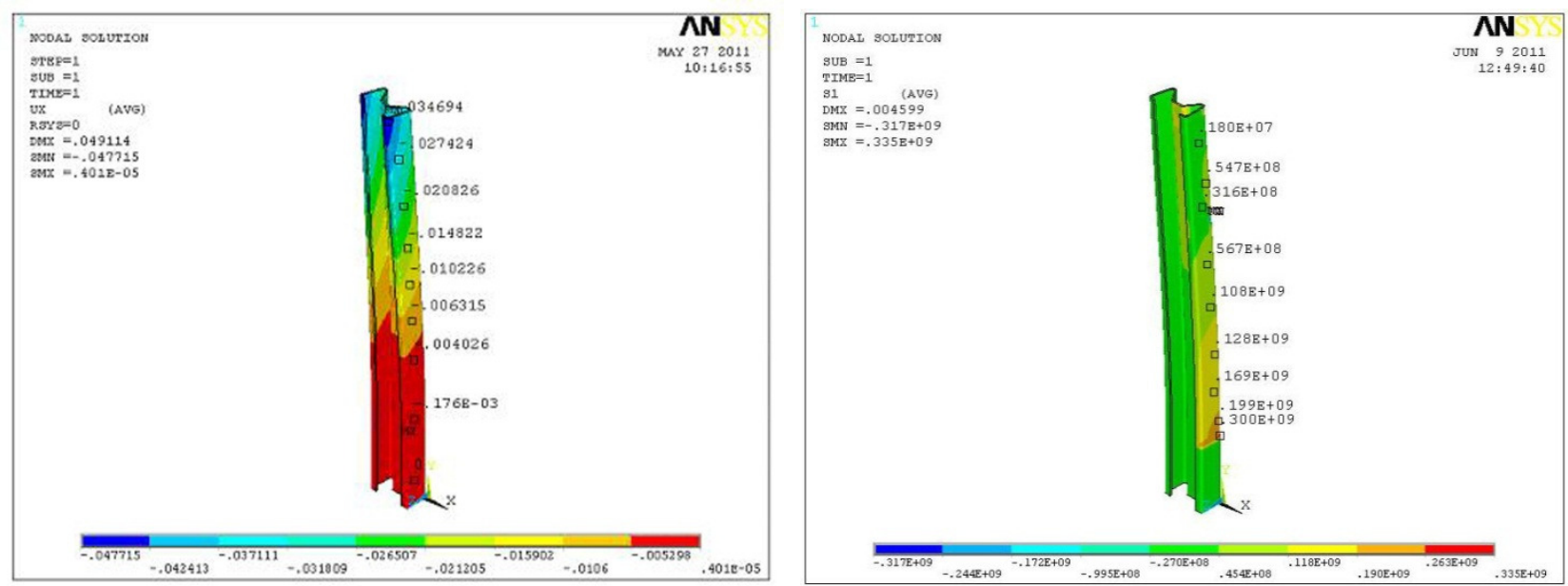

a)

b)

Fig. 11. The post MST-2 mounted on a bridge or a viaduct: $a$ - deflections, $b$ - stresses (our research)
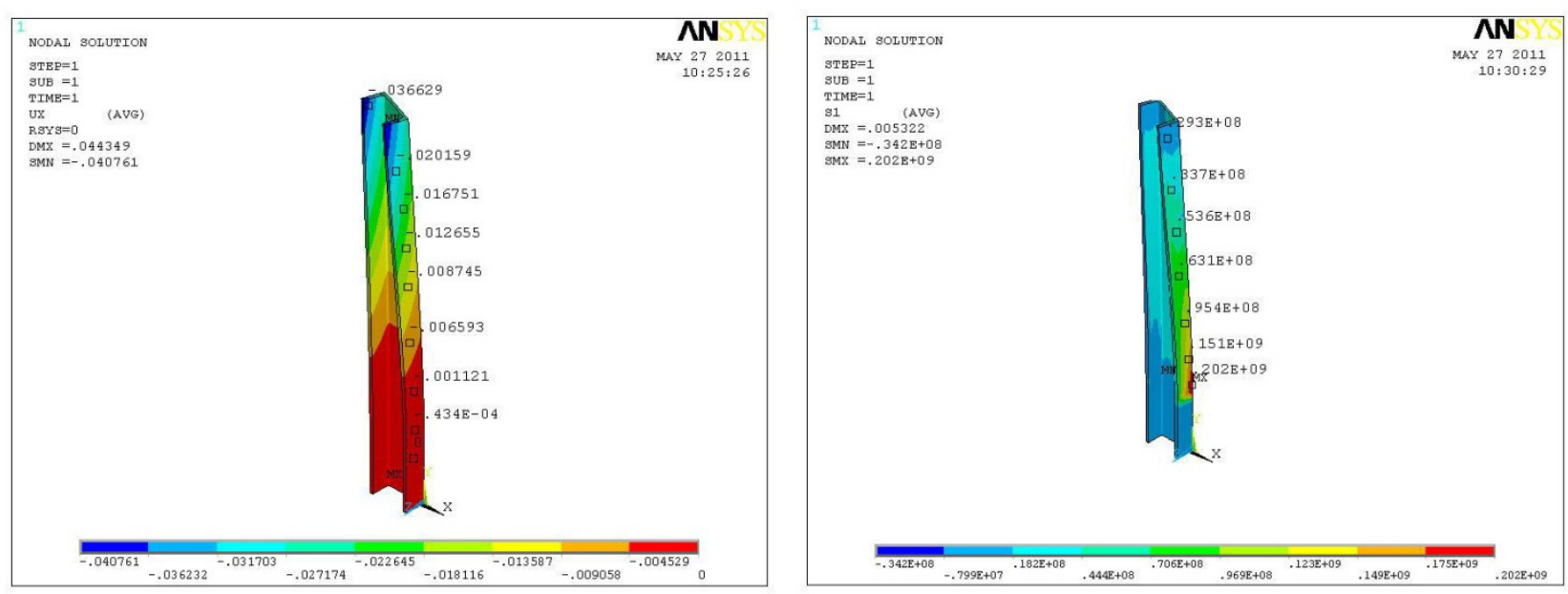

a)

b)

Fig. 12. The post MST-3 mounted on a bridge or a viaduct: $a$ - deflections, b - stresses (our research) 


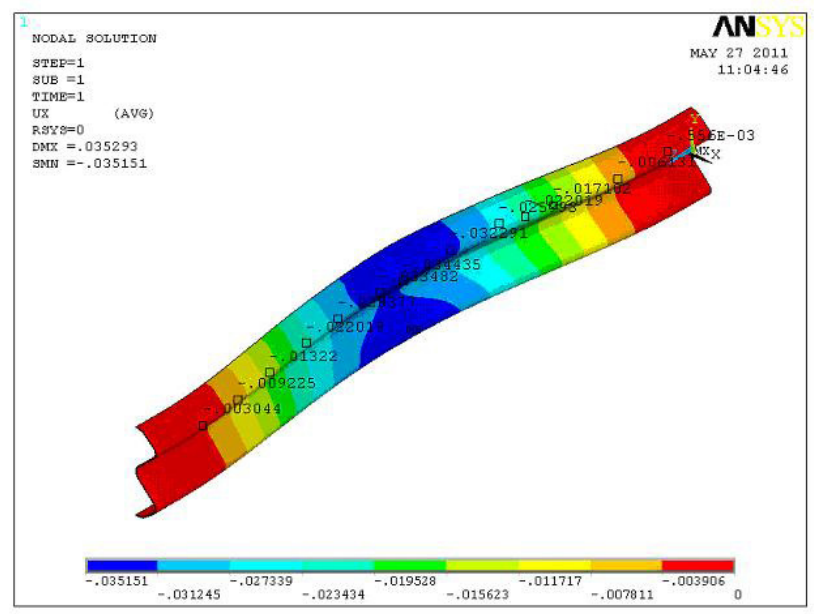

a)

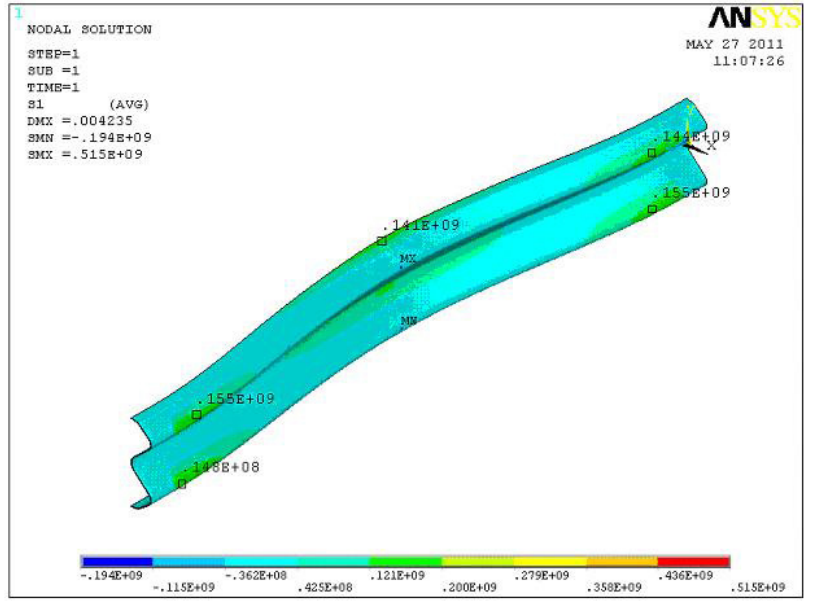

b)

Fig. 13. Beams of the guardrail MS-A: a - deflections, $b$ - stresses (our research)

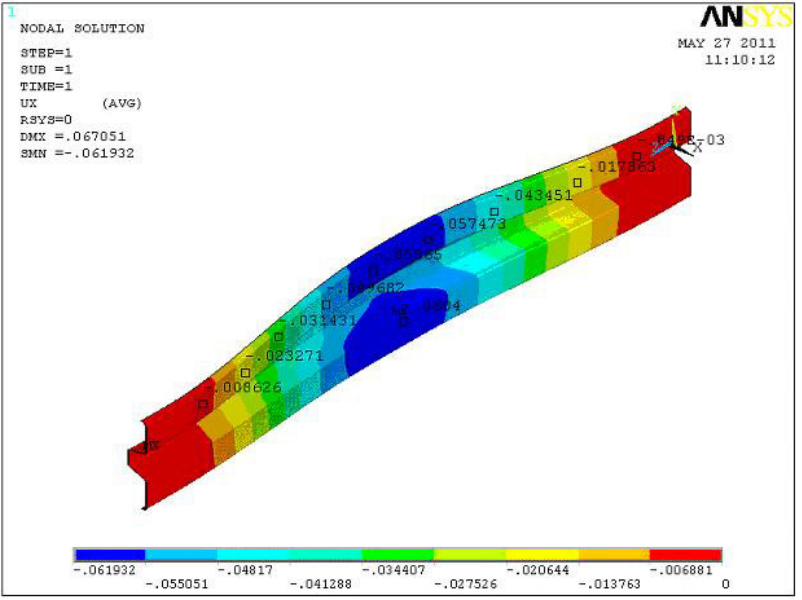

a)

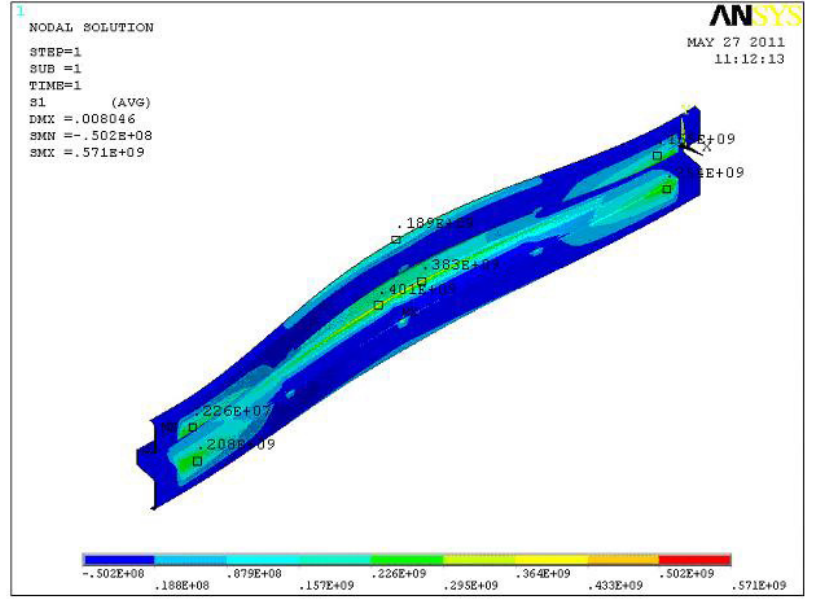

b)

Fig. 14. Beams of the guardrail MS-B: a - deflections, $b$ - stresses (our research)

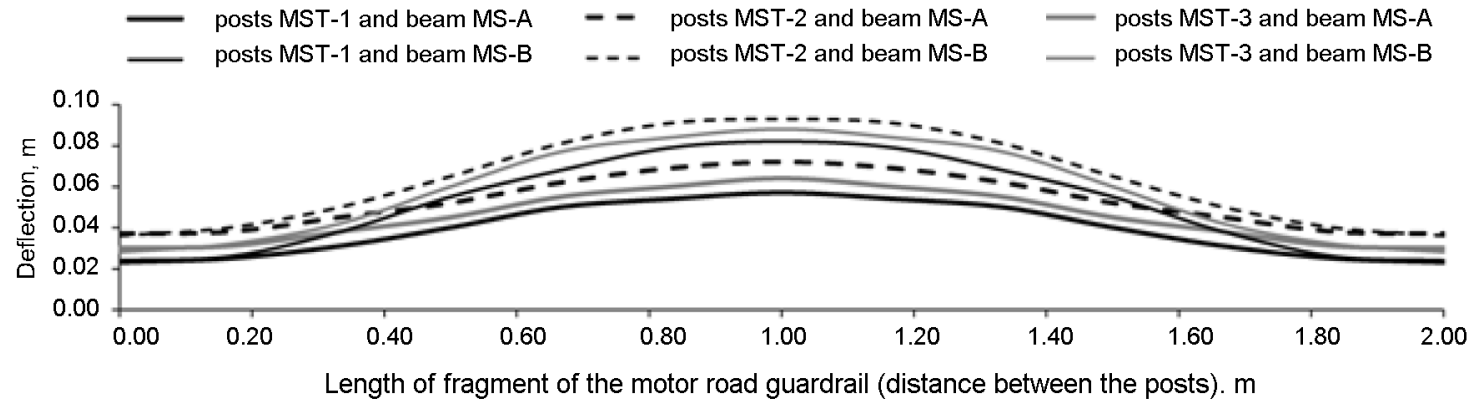

Fig. 15. The comparison of deflections of guardrails mounted on bridges or viaducts (our research)

The stresses developed in the guardrail beams MS-A and MS-B were similarly distributed. The highest stresses were found in the middle part of the beam, acted upon by the impact force of the vehicle, and, in the areas, where the beam was fixed to the posts (Figs 13-14).

\section{General results of guardrail analysis}

The comparative analysis of the models, describing the guardrail as a whole, has shown that the deformation found in the model, representing the guardrail made of the posts MST-2 and the beam MS-B, was the highest. The deflection of $9.3 \mathrm{~cm}$ found in this model, was the largest (Fig. 15). 
The main function of the guardrail, mounted on a bridge or a viaduct, is to keep a vehicle, colliding with it, on the road. In this case, the deflection of the guardrail should be as small as possible. Therefore, for guardrails mounted on bridges or viaducts, the the posts MST-1 and the beam MS-A (with the deflection of $5.7 \mathrm{~cm}$ ) are preferable. However, the comparative analysis shows that the numerical values of deflections do not differ considerably.

The largest deflection $(9.3 \mathrm{~cm})$ was found for the model, representing the guardrail made of the posts MST-2 and the beam MS-B (Fig. 15). The guardrail of this model is the best in absorbing the impact energy, produced by a vehicle colliding with a guardrail. The deflection of $9.3 \mathrm{~cm}$ is not large and, in this case, the guardrail should keep the vehicle, colliding with it in the traffic lane. Therefore, taking into account all the data obtained in the analysis, it may be concluded that the guardrail, consisting of the posts MST-2 and the beam MS-B, is the best alternative for bridges or viaducts.

\section{Conclusions}

1. The presented statistical data on traffic accidents on the roads of Lithuania show that, in recent years, their number has decreased, though many people are still killed on the road. Therefore, to improve traffic safety in various countries, public education on the problems of traffic safety, as well as the control of traffic rules violation should be more effective.

2. The analysis of the literature on the problem has shown that testing of motor road guardrails may be performed for the whole guardrail or for its separate parts. The comparative analysis of the results obtained in computer simulation and real tests shows that computer models are sufficiently accurate and well suited for guardrail testing, while their cost is considerably lower.

3. According to the Standard Construction Recommendations R37-1, Design Rules KPT TAS 09 and Lithuanian Standard LST EN 1317 metal beam guardrails, consisting of the components given below, are used on Lithuanian and Ukrainian roads (the analogical standards are valid for guardrails mounted in Ukraine - GOST 26804-86 valid till 30 November 2012, DSTU 2735-94, DSTU 3587-97, DSTU B V.2.3-28:2011 valid since 1 December 2012): the beams MS-A (a metal beam A) and MS-B (a metal beam B), the posts MST-1 (a metal post 1), MST-2 (a metal post 2) and MST-3 (a metal post 3). The posts MST- 2 and the beams MS-A are most commonly used.

4. Based on the use of the guardrail model, created and investigated with the help of the software package ANSYS, it may be stated that, in the guardrail model used on a bridge or a viaduct, the smallest deflection is in the post MST-1 $(2.6 \mathrm{~cm})$, while the largest - in the post MST-2 $(4.9 \mathrm{~cm})$. The bridge or viaduct guardrails should be deformed as little as possible to be able to keep the vehicles, colliding with them, in their traffic lanes. The kinetic energy, transferred by a vehicle colliding with a guardrail, becomes a minor problem in this case.
5. The results obtained in the analysis of the guardrail beams were contradictory. Unexpectedly, the beam MS-B turned out to be more heavily deformed than the beam MSA. Their deflections were $6.7 \mathrm{~cm}$ and $3.5 \mathrm{~cm}$, respectively. Thus, it may be concluded that the beam MS-A is preferable for guardrails, mounted on bridges or viaducts.

6. The tests performed with all guardrail models showed that, for the guardrail mounted on a bridge or a viaduct, the threshold deflection $(5.7 \mathrm{~cm})$ was the smallest in the case, when the posts MST-1 and the beam MS-A were used. However, the numerical values of the largest threshold deflection for the guardrail, consisting of the post MST-2 and the beam MS-B, was not large $(9.3 \mathrm{~cm})$. Therefore, it is reasonable to believe that this guardrail should be able to keep the vehicle, colliding with it, in its traffic lane (meaning that the vehicle would not fall down from the bridge or viaduct) and absorb more impact energy of a vehicle than the guardrail with the posts MST- 1 and the beam MS-A.

\section{References}

Abtahi, S. M.; Tamannaei, M.; Haghshenash, H. 2011. Analysis and modeling time headway distributions under heavy traffic flow conditions in the urban highways: case of Isfahan, Transport 26(4): 375-382.

http://dx.doi.org/10.3846/16484142.2011.635694

Accident Rate Information. 2011. The Lithuanian Road Administration under the Ministry of Transport and Communications of the Republic of Lithuania. Available from Internet: http://www.lra.lt/en.php/traffic_safety/accident_rate_ information/106

Ambroziak, A.; Korzeniowski, M. 2010. Using resistance spot welding for joining aluminium elements in automotive industry, Archives of Civil and Mechanical Engineering 10(1): 5-13. http://dx.doi.org/10.1016/S1644-9665(12)60126-5

Bayton, D. A. F.; Jones, T. B.; Fourlaris, G. 2008. Analysis of a safety barrier connection joint post-testing, Materials and Design 29(5): 915-921.

http://dx.doi.org/10.1016/j.matdes.2007.04.010

Beljatynskij, A.; Kuzhel, N.; Prentkovskis, O.; Bakulich, O.; Klimenko, I. 2009. The criteria describing the need for highway reconstruction based on the theory of traffic flows and repay time, Transport 24(4): 308-317. http://dx.doi.org/10.3846/1648-4142.2009.24.308-317

Bień, J. 2011. Modelling of structure geometry in bridge management systems, Archives of Civil and Mechanical Engineering 11(3): 519-532. http://dx.doi.org/10.1016/S1644-9665(12)60099-5

Černiauskas, E.; Keršys, A.; Lukoševičius, V.; Sapragonas, J. 2010. Investigation of anti-intrusion beams in vehicle side doors, Mechanika (6): 11-16.

Dargužis, A.; Sapragonas, J.; Pilkauskas, K. 2011. Dynamic processes of a vehicle moving over step-shaped obstacles, Journal of Vibroengineering 13(3): 536-543.

Dell'Acqua, G.; Russo, F. 2011. Safety performance functions for low-volume roads, The Baltic Journal of Road and Bridge Engineering 6(4): 225-234.

http://dx.doi.org/10.3846/bjrbe.2011.29

DSTU 2735-94. Ogorodzhennia dorozhni i napriamni prystroji. Pravila vykorystannia. Vymogy bezpeky dorozhniogo ruchu (in Ukrainian). 
DSTU 3587-97. Bezpeka dorozhniogo ruhu. Avtomobil'ni dorogy, vulyci ta zaliznychni perejizdy. Vymogy do ekspluatacijnogo stanu (in Ukrainian).

DSTU B V.2.3-28:2011. Ogorodzhuvannia dorozhni metalevi bar'jernogo tipu. Tehnichi umovy (in Ukrainian).

Ferdous, M. R.; Abu-Odeh, A.; Bligh, R. P.; Jones, H. L.; Sheikh, N. M. 2011. Performance limit analysis for common roadside and median barriers using LS-DYNA, International Journal of Crashworthiness 16(6): 691-706. http://dx.doi.org/10.1080/13588265.2011.623023

Grīslis, A. 2010. Longer combination vehicles and road safety, Transport 25(3): 336-343.

http://dx.doi.org/10.3846/transport.2010.41

GOST 26804-86. Ograzhdeniia dorozhnyje metallicheskie bar'jernogo tipa. Technicheskie usloviia (in Russian).

Hampton, C. E.; Gabler, H. C. 2012. Crash performance of strong-post W-beam guardrail with missing blockouts, International Journal of Crashworthiness 17(1): 93-103. http://dx.doi.org/10.1080/13588265.2011.626931

Hartleb, J.; Ketting, M. 2011. Stable algorithm to simulate dynamic undercarriage loads of tracked vehicles, Archives of Civil and Mechanical Engineering 11(4): 867-874. http://dx.doi.org/10.1016/S1644-9665(12)60083-1

Hassan, H. F.; Al-Jabri, K. 2011. Laboratory evaluation of hotmix asphalt concrete containing copper slag aggregate, Journal of Materials in Civil Engineering 23(6): 879-885. http://dx.doi.org/10.1061/(ASCE)MT.1943-5533.0000246

Iluk, A.; Rusiński, E. 2011. Strength analysis of the kinematic pairs of a mobile collapsible bridge, Archives of Civil and Mechanical Engineering 11(4): 875-884.

http://dx.doi.org/10.1016/S1644-9665(12)60084-3

Jablonskytė, J.; Ilgakojytė-Bazarienė, J.; Keršys, A.; Pakalnis, A. 2011. Research of congestions in urban transport network using cellular automation model, Transport 26(2): 158165.

http://dx.doi.org/10.3846/16484142.2011.586107

Jahangiri, A.; Afandizadeh, S.; Kalantari, N. 2011. The optimization of traffic signal timing for emergency evacuation using the simulated annealing algorithm, Transport 26(2): $133-140$.

http://dx.doi.org/10.3846/16484142.2011.584959

Jakimavičius, M.; Burinskienè, M. 2010. Route planning methodology of an advanced traveller information system in Vilnius city, Transport 25(2): 171-177. http://dx.doi.org/10.3846/transport.2010.21

Jović, J.; Đorić, V. 2010. Traffic and environmental street network modelling: Belgrade case study, Transport 25(2): 155-162. http://dx.doi.org/10.3846/transport.2010.19

Keršys, A.; Pakalnis, A.; Lukoševičius, V. 2011. Investigation of occupant fatalities and injuries during the impact of vehicle and road safety barrier, The Baltic Journal of Road and Bridge Engineering 6(1): 5-11.

http://dx.doi.org/10.3846/bjrbe.2011.01

Kopczyński, A.; Ptak, M.; Harnatkiewicz, P. 2011. The influence of frontal protection system design on pedestrian passive safety, Archives of Civil and Mechanical Engineering 11(2): 345-364.

http://dx.doi.org/10.1016/S1644-9665(12)60148-4

KPT TAS 09. 2010. Automobiliu keliu transporto priemoniu apsauginiu atitvaru sistemu projektavimo taisykles (in Lithuanian).

Krayushkina, K.; Prentkovskis, O.; Bieliatynskyi, A.; Junevičius, R. 2012. Use of steel slags in automobile road construction, Transport 27(2): 129-137.

http://dx.doi.org/10.3846/16484142.2012.690093
Li, W.; Sun, P.; Zhang, C. 2012. Laboratory test study on asphalt concrete with steel slag aggregates, Applied Mechanics and Materials 152-154: 117-120. http://dx.doi. org/10.4028/www.scientific.net/AMM.152-154.117

Logan, D. L. 2011. A First Course in the Finite Element Method. 5th edition. CL Engineering. 992 p.

LST EN 1317. Apsauginiu kelio atitvary sistemos [Road Restraint Systems].

Maksymowicz, M.; Cruz, P. J. S.; Bień, J. 2011. Load capacity of damaged RC slab spans of railway-bridges, Archives of Civil and Mechanical Engineering 11(4): 963-978. http://dx.doi.org/10.1016/S1644-9665(12)60089-2

Matis, P. 2010. Finding a solution for a complex street routing problem using the mixed transportation mode, Transport 25(1): 29-35. http://dx.doi.org/10.3846/transport.2010.05

Mohan, P.; Marzougui, D.; Meczkowski, L.; Bedewi, N. 2005. Finite element modeling and validation of a 3 -strand cable guardrail system, International Journal of Crashworthiness 10(3): 267-273.

http://dx.doi.org/10.1533/ijcr.2005.0345

Moaveni, S. 2008. Finite Element Analysis: Theory and Application with ANSYS. 3rd edition. Pearson Education. 822 p.

Mucha, J.; Kaščák, L.; Spišák, E. 2011. Joining the car-body sheets using clinching process with various thickness and mechanical property arrangements, Archives of Civil and Mechanical Engineering 11(1): 135-148. http://dx.doi.org/10.1016/S1644-9665(12)60179-4

Mučinis, D.; Sivilevičius, H.; Oginskas, R. 2009. Factors determining the inhomogeneity of reclaimed asphalt pavement and estimation of its components content variation parameters, The Baltic Journal of Road and Bridge Engineering 4(2): 69-79.

http://dx.doi.org/10.3846/1822-427X.2009.4.69-79

Prentkovskis, O.; Beljatynskij, A.; Prentkovskienè, R.; Dyakov, I.; Dabulevičiene, L. 2009. A study of the deflections of metal road guardrail elements, Transport 24(3): 225-233. http://dx.doi.org/10.3846/1648-4142.2009.24.225-233

Prentkovskis, O.; Beljatynskij, A.; Juodvalkienè, E.; Prentkovskienè, R. 2010a. A study of the deflections of metal road guardrail post, The Baltic Journal of Road and Bridge Engineering 5(2): 104-109. http://dx.doi.org/10.3846/bjrbe.2010.15

Prentkovskis, O.; Sokolovskij, E.; Bartulis, V. 2010b. Investigating traffic accidents: a collision of two motor vehicles, Transport 25(2): 105-115. http://dx.doi.org/10.3846/transport.2010.14

Ptak, M.; Rusiński, E.; Karliński, J.; Dragan, S. 2012. Evaluation of kinematics of SUV to pedestrian impact - lower leg impactor and dummy approach, Archives of Civil and Mechanical Engineering 12(1): 68-73.

http://dx.doi.org/10.1016/j.acme.2012.03.016

R37-01. 2001. Automobiliu keliu apsauginiai atitvarai. Statybos rekomendacijos. 32 p. (in Lithuanian).

Ren, Z.; Vesenjak, M. 2005. Computational and experimental crash analysis of the road safety barrier, Engineering Failure Analysis 12(6): 963-973. http://dx.doi.org/10.1016/j.engfailanal.2004.12.033

Sapragonas, J.; Dargužis, A. 2011. Model of radial deformations of protector of vehicle tire, Mechanika 17(1): 2129. http://dx.doi.org/10.5755/j01.mech.17.1.199

Sharma, N.; Arkatkar, S. S.; Kumar, A. 2011. Study on heterogeneous traffic flow characteristics of a two-lane road, Transport 26(2): 185-196.

http://dx.doi.org/10.3846/16484142.2011.593120 
Sivilevičius, H. 2011a. Application of expert evaluation method to determine the importance of operating asphalt mixing plant quality criteria and rank correlation, The Baltic Journal of Road and Bridge Engineering 6(1): 48-58. http://dx.doi.org/10.3846/bjrbe.2011.07

Sivilevičius, H. 2011b. Modelling the interaction of transport system elements, Transport 26(1): 20-34. http://dx.doi.org/10.3846/16484142.2011.560366

Sivilevičius, H.; Podvezko, V.; Vakrinienè, S. 2011. The use of constrained and unconstrained optimization models in gradation design of hot mix asphalt mixture, Construction and Building Materials 25(1): 115-122.

http://dx.doi.org/10.1016/j.conbuildmat.2010.06.050

Stanić, B.; Tubić, V.; Čelar, N. 2011. Straight lane saturation flow and its rate in Serbian cities, Transport 26(3): 329334. http://dx.doi.org/10.3846/16484142.2011.623762

Stolle, C. S.; Reid, J. D. 2011. Development of a wire rope model for cable guardrail simulation, International Journal of Crashworthiness 16(3): 331-341.

http://dx.doi.org/10.1080/13588265.2011.586609

STR 2.05.04:2003. Statybos techninis reglamentas: poveikiai ir apkrovos (in Lithuanian)

Tan, K. S.; Tan, W.; Wong, S. V. 2008. Design of motorcyclistfriendly guardrail using finite element analysis, International Journal of Crashworthiness 13(5): 567-577. http://dx.doi.org/10.1080/13588260802293186
Wang, G.; Thompson, R. G.; Wang, Y. 2011a. Hot-mix asphalt that contains nickel slag aggregate, Transportation Research Record 2208: 1-8.

http://dx.doi.org/10.3141/2208-01

Wang, Y.-G.; Chen, K.-M.; Pei, Y.-L.; Wang, Y. 2011b. Integrating before and after crash features into measuring the effectiveness of intersection safety improvement project in Harbin, Transport 26(1): 111-120. http://dx.doi.org/10.3846/16484142.2011.565599

Wu, W.; Thomson, R. 2005. Effects of front wheels and steering-suspension systems during vehicle oblique collisions with a flared guardrail terminal, International Journal of Crashworthiness 10(5): 495-503. http://dx.doi.org/10.1533/ijcr.2005.0364

$\mathrm{Wu}, \mathrm{W}$.; Thomson, R. 2007. A study of the interaction between a guardrail post and soil during quasi-static and dynamic loading, International Journal of Impact Engineering 34(5): 883-898. http://dx.doi.org/10.1016/j.ijimpeng.2006.04.004

Zienkiewicz, O. C.; Taylor, R. L.; Zhu, J. Z. 2005. The Finite Element Method: Its Basis and Fundamentals. 6th edition. Butterworth-Heinemann. $752 \mathrm{p}$.

Žiliūtè, L.; Laurinavičius, A.; Vaitkus, A. 2010. Investigation into traffic flows on high intensity streets of Vilnius city, Transport 25(3): 244-251. http://dx.doi.org/10.3846/transport.2010.30

Olegas PRENTKOVSKIS. Doctor, Associate Professor, Department of Transport Technological Equipment, Vilnius Gediminas Technical University, Lithuania. Research interests: vehicles dynamics, simulation of traffic accidents, traffic safety problems, transport infrastructure, numerical methods.

Jurijus TRETJAKOVAS. Doctor, Associate Professor, Department of Strength of Materials, Vilnius Gediminas Technical University, Lithuania. Research interests: finite element method, nonlinear mechanics, fracture mechanics.

Audrius ŠVEDAS. MSc, Traffic Accidents Expert, Forensic Science Centre of Lithuania. Research interests: investigation of traffic accidents, traffic safety problems.

Andrii BIELIATYNSKYI. Doctor, Professor, Department of Airport Reconstruction and Automobile Roads, Institute of Airports, National Aviation University, Ukraine. Research interests: motor road engineering, traffic flow, traffic safety problems.

Alfonsas DANIŪNAS. Doctor, Associate Professor, Department of Steel and Timber Structures, Vilnius Gediminas Technical University, Lithuania. Research interests: analysis and optimization of elastic and plastic steel structures, numerical methods, semi-rigid joints of steel structures.

Kateryna KRAYUSHKINA. Engineer, Doctoral Student, Department of Airport Reconstruction and Automobile Roads, Institute of Airports, National Aviation University, Ukraine. Research interests: road building materials and technologies, de-icing materials, traffic safety problems. 